\title{
A Nona Arte na
}

Amazônia: um

panorama do cenário

de histórias em

quadrinhos em Belém ${ }^{1}$

Juliana Angelim²

Universidade Federal do Pará

Resumo: Ainda que o mercado brasileiro de histórias em quadrinhos seja amplamente caracterizado pela importação de outros países, é inegável a existência de uma significativa produção de histórias em quadrinhos nacionais - e regionais. No Pará, por exemplo, a década de 1970 representou o início da publicação de histórias em quadrinhos criadas por paraenses em jornais do estado, além do lançamento de concursos e editais para incentivar os interessados em publicar suas próprias histórias. Belém foi palco do surgimento de grupos que, durante anos, fomentaram a interação e a produção de diversos quadrinistas. Fanzines e revistas de quadrinhos saíram, resultantes da atuação desses grupos, dentre os quais se destacam o fanzine Ponto de Fuga (em várias edições, elaborado pelo grupo Ponto de Fuga) e o título Catarse Quadrinhos (em edição única, viabilizada a partir da contemplação do grupo Catarse com o Prêmio IAP de Edições Culturais do ano de 2008). Ademais, revistas independentes, fruto do trabalho conjunto de alguns quadrinistas (não necessariamente reunidos sob o nome de um grupo) ou de um único responsável, também compóem o quadro geral de histórias em quadrinhos belenenses. Belém Imaginária, Encantarias - a lenda da noite e Pretérito mais que perfeito são exemplos de histórias em quadrinhos produzidas na capital paraense que adquiriram repercussão inclusive em outros estados; enquanto que Volney Nazareno, Otoniel Oliveira e Carlos Paul são alguns dos nomes por trás das publicações. Dito isso, o objetivo deste trabalho é apresentar um panorama do cenário de histórias em quadrinhos em Belém, abordando títulos e quadrinistas; formação e atuação de grupos; concursos, editais, patrocínios privados e outras formas de viabilização financeira; eventos locais e espaços de circulação das histórias, dentre outros pontos relevantes à proposta.

Palavras-chaveः histórias em quadrinhos; cenário; Belém.

Abstract: Although the Brazilian comics market is largely characterized by imports from other countries, a significant production of national and regional comics is undeniable. In the state of Pará (Brazil), for example, the 1970s represented the beginning of the publication of comics created by local authors for newspapers of the state, as well as the
1. Trabalho vencedor do Prêmio Álvaro de Moya de Incentivo à Pesquisa em Quadrinhos de 2018, concedido ao melhor trabalho apresentado às 4as Jornadas Internacionais de Histórias em Quadrinhos, realizadas de 22 a 25 de agosto de 2017. 0 prêmio é destinado a reconhecer e valorizar os pesquisadores que participam a cada edição desse evento científico.

2. Bacharel em Comunicação Social (Jornalismo) pela Universidade Federal do Pará. Mestranda do Programa de Pós-Graduação em História Social da Amazônia, da Universidade Federal do Pará (UFPA), sob a orientação do Prof. Dr. Antônio Maurício Dias da Costa. O artigo constitui resultado parcial de sua pesquisa de mestrado, intitulada A nona arte na Amazônia: um estudo sobre a representação da cultura amazônica nas histórias em quadrinhos belenenses (2004-2017). 
3.Além da atuação como jornalista, João de Jesus Paes Loureiro é poeta, prosador e ensaísta. No final da década de 1980, assumiu a presidência da Fundação Cultural do Pará Tancredo Neves e foi Secretário de Estado da Cultura (Secult). Atualmente, é professor voluntário na Universidade Federal do Pará, com experiência na área de Artes e Comunicação. Informações retiradas do Blog do Paes Loureiro. Disponível em: https://paesloureiro.wordpress. com/paesloureiro/. Acesso em: 7 ago. 2017) e do Currículo da Plataforma Lattes. Disponível em: http://lattes. cnpq.br/2018214713424265. Acesso em: 7 ago. 2017).

4. Localizada na Avenida Gentil Bittencourt, no bairro Nazaré. A partir de 2015, a Fundação Cultural do Pará Tancredo Neves (atualmente, Sede "Centur") torna-se o Prédio Sede da Fundação Cultural do Estado do Pará (FCP), abrigando os seguintes espaços culturais: Biblioteca Pública Arthur Vianna, Centro de Eventos Ismael Nery, Teatro Margarida Schivasappa, Cine-Teatro Líbero Luxardo, Galeria Theodoro Braga, Fonoteca Pública Satyro de Mello, além de halls e duas praças internas. A Fundação Cultural do Pará, por sua vez, compreende outras quatro unidades: a Casa da Linguagem, o Núcleo de Oficinas Curro Velho (anteriormente, Fundação Curro Velho), a Casa das Artes (outrora, Instituto de Artes do Pará ou IAP) e o Teatro Experimental Waldemar Henrique. Disponível em: http:// www.fcp.pa.gov.br/. Acesso em: 24 jul. 2017.

launching of contests and calls to encourage those artists interested in publishing their own comics. The city of Belém was the place for the emergence of groups that, for years, fostered the interaction and production of several comics artists. Fanzines and comic books resulted from the performance of these groups, among them the fanzine Ponto de Fuga (in several issues, elaborated by the group Ponto de Fuga) and the title Catarse Comics (in a single edition, made possible by the obtaining of the IAP Prize of Cultural Editions of the year 2008 by Catarse). In addition, independent magazines, the result of combined work of several comics artists (not necessarily gathered under the name of a group) or of a single person, also compose the framework of comics from Belém. Belém Imaginária, Encantarias - a lenda da noite and Pretérito mais que perfeito are examples of comics produced in the capital of Pará that have had repercussions even in other states; Volney Nazareno, Otoniel Oliveira and Carlos Paul are some of the names behind the publications. The objective of this work is to present an overview of the comics scenario in Belém, focusing on titles and artists; the establishment of groups and their activities; competitions, public support, private sponsorships and other forms of financial viability; local events and spaces of circulation of comics, among other relevant points to the proposal.

Keywordsः comics; comics framework; Belém.

Introdução: Os primeiros quadrinhos amazônicos

Convidei o Bechara Gaby - ou, apenas GABY como ele prefere assinar - para uma experiência fascinante em nossa página: realizar a primeira história em quadrinhos amazônica. Convidei-o por vários motivos justos. Pela confiança que tenho em sua criatividade, pelo seu conhecimento sobre o assunto em têrmos estéticos e culturais, pela pureza de seu traço. Além disso, o seu entusiasmo e capacidade de trabalho, permitiram-me estender o convite para publicação de desenhos, caricaturas e ilustrações (LOUREIRO, 1972, p.2).

Com essas palavras, João de Jesus Paes Loureiro ${ }^{3}$ inicia o texto referente ao título "Está lançado o quadrinho", em um caderno de cultura que ele editava no jornal Folha do Norte, em 1972. A primeira história em quadrinhos em questão foi, na verdade, uma entrevista em quadrinhos, realizada com o grupo de teatro "GRUPAÇÃO". Depois disso, ainda naquele ano, o à época estudante de arquitetura Bichara Gaby organizou o primeiro concurso de histórias em quadrinhos, tendo como vencedor o belenense Onofre Arcleidy Pereira. Tamanha foi a repercussão do concurso que dele adveio o primeiro suplemento infantil vinculado a um jornal belenense - O Liberalzinho, do jornal O Liberal (VHQ, 2015).

Nos anos de 1988 e 1989, coube ao Governo do Estado do Pará, através da Secretaria da Cultura e da Fundação Cultural do Pará Tancredo Neves ${ }^{4}$, incentivar a produção local de quadrinhos, com o lançamento do chamado Edital de Arte. Como resultado, foram publicados um total de seis álbuns de quadrinhos, três para cada ano, dos quais destacamos Quando eu esquecer do teu beijo, de Branco Medeiros e Betto Paiva; Jesus Cristo Superstar, de Paulo Emmanuel; e Vero-Pexe e sua turma, de Luiz Paulo Jacob e Gabriel de Jesus (Figura 1). 


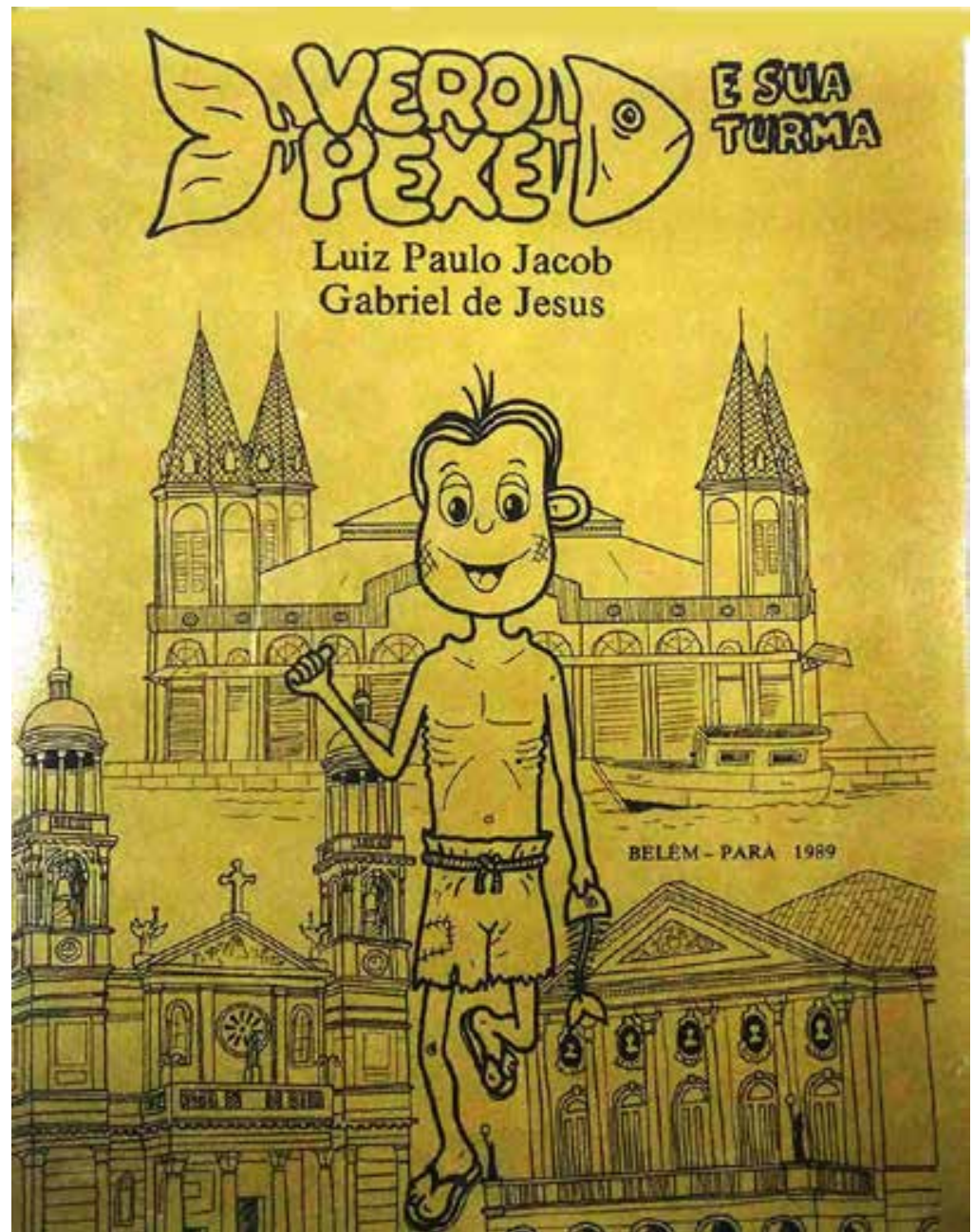

Figura 1 - Capa do álbum Vero-Pexe e sua turma, contemplado pelo Edital de Arte de 1988. Fonte: Acervo da autora

\section{1 - Os artistas e suas obras}

É interessante elucidar que, em sua carreira como artista gráfico, Branco Medeiros experimentou os quadrinhos de outras formas que não demandassem o suporte físico manuseável característico do álbum Quando eu esquecer do teu beijo. Primeiramente, promoveu três exposiçóes - Krigh-Ah Bandolo!, O homem moeda e Bandidos da paixão -, onde, literalmente, "enquadrou" páginas de quadrinhos, apresentando-as em quadros numa galeria. Ademais, Branco é apontado como o primeiro desenhista paraense a elaborar histórias em quadrinhos no computador, a partir de 1990 (BELÉM..., 1991).

Já Paulo Emmanuel - que, segundo consta em seu portfólio ${ }^{5}$, iniciou carreira em 1987, publicando ilustrações e charges no jornal A Provincia do Pará -, revela-se um dos nomes pioneiros na publicação de fanzines com histórias em quadrinhos ${ }^{6}$, tendo como grande expoente de sua produção o Zambrazine, lançado a partir de 1990. Entretanto, atribui-se ao ano de 1989 a criação do primeiro fanzine exclusivamente de quadrinhos em Belém: trata-se do Crash, de Gian Danton e de Bené Nascimento 7 .

Em 1985 - num período anterior ao Crash, portanto -, Bené Nascimento já tinha entrado para o mercado nacional de quadrinhos, por meio da produção de histórias dos gêneros terror e erótico para a editora Press Editorial. Posteriormente, passou a trabalhar com outras editoras,
5. Disponível em: https://issuu.com/ zambra/docs/portfolioscompleto. Acesso em: 17 jul. 2017.

6. Importa constatar que, no Brasil, convencionou-se tomar o veículo de comunicação alternativo chamado de fanzine como qualquer publicação independente, sendo esta composta apenas de histórias em quadrinhos, de poesias ou de textos sobre assuntos específicos, ou, também, abrangendo mais de um ou todos esses conteúdos (ANDRAUS, 2011, p.182).

7. Curiosamente, "Gian Danton" é o pseudônimo de Ivan Carlo Andrade de Oliveira, roteirista e pesquisador de histórias em quadrinhos, enquanto que "Bené Nascimento" (ou melhor, "Benedito José Nascimento") é o verdadeiro nome do mundialmente conhecido "Joe Bennett", desenhista contratado pela editora Marvel. 
8. Situada na Avenida Nazaré, esquina da Avenida Assis de Vasconcelos, a Casa da Linguagem abriga a Biblioteca Francisco Paulo Mendes, bem como auditório/ cinema, galeria e instalações voltadas para cursos, oficinas e programações centradasemações de linguagem verbal. Disponível em: http://www.fcp.pa.gov.br/. Acesso em: 24 jul. 2017. tendo publicado junto à Nova Sampa o título $A$ insólita família titãa, escrita pelo já consolidado parceiro Gian Danton. A história em quadrinhos alcançou tamanha vendagem que chamou a atenção do dono do estúdio Art $\mathcal{E}$ Comics, que agencia artistas brasileiros no mercado estadunidense de quadrinhos (SAKS, 2016, p.39). Como resultado, em 1992, Bené conseguiu seu primeiro trabalho nos Estados Unidos (sem nunca ter deixado de morar em Belém, vale mencionar), passando por várias editoras pequenas até que, em 1994, foi chamado pela Marvel para desenhar seus super-heróis, onde começou com personagens menos conhecidos até chegar aos mais famosos, como X-Men, Homem Aranha e Capitão América (CUNHA, 1993, p.4-5).

Gian Danton é jornalista (inclusive, várias matérias publicadas n'O Liberal a respeito do tema histórias em quadrinhos foram de sua autoria), roteirista de quadrinhos e professor universitário. Participou da criação de quadrinhos lançados, dentre outras editoras, pela Metal Pesado, Via Lettera e ICEA, além de ter publicado obras literárias de ficção e livros sobre escrita e roteiro de histórias em quadrinhos. Consta que sua estreia como roteirista no mercado de quadrinhos brasileiro se deu em 1989, com a publicação de Floresta Negra, na revista Calafrio (SAKS, 2016, p.38). E, juntando esta história, que também foi desenhada por Bené, com os já mencionados fanzine Crash e a popular A insólita família titã, temos alguns resultados do que se mostrou ser uma fecunda parceria entre os dois quadrinistas; parceria que pode ser traduzida, sobretudo, na produção de quadrinhos de terror em uma época antecedente à entrada de Bené no mercado dos Estados Unidos.

\section{2 - Espaços de produção e divulgação}

No que concerne propriamente à cena de quadrinhos em Belém, a contribuição de Gian e Bené excedeu a repercussão de seus títulos publicados. Isso porque, em 1991, a partir de uma oficina de quadrinhos que eles ministraram no "Centur", surgiu o primeiro grupo de quadrinistas na capital paraense: o Ponto de Fuga (NEGRÃO, 2011, p.21). Os materiais produzidos pelos participantes da oficina logo se converteram no número zero de um fanzine batizado com o mesmo nome do grupo, e numa exposição, também denominada Ponto de Fuga (FANZINE..., 1992). Daí em diante, produção de fanzines e organização de eventos de quadrinhos seriam uma constante no currículo do grupo, que, inclusive, foi responsável pela realização do I Dia Nacional das Histórias em Quadrinhos em Belém (NEGRÃO, 2011, p.20), que ocorreu na Casa da Linguagem ${ }^{8}$, em 1992.

"Incentivar a criação de espaços de pesquisa, produção e lazer denominados Gibitecas, assim como reunir pesquisadores e colecionadores de histórias em quadrinhos" (NEGRÃO, 2011, p.21) também foi um dos objetivos do Ponto de Fuga, de forma que, não por acaso, seus integrantes estiveram envolvidos na instituição de três gibitecas em Belém. Uma delas foi criada pelo próprio grupo e implementada no espaço que ficou conhecido como Na Morada da Arte, onde funcionou a sede do Ponto de Fuga e de outras seis associações artísticas, a saber: Federação Estadual dos Atores, Autores e Técnicos de Teatro (Fesat); Associação de Compositores, Letristas, Intérpretes e Músicos do Pará (Clima); Associação Paraense de Dança (APAD); Malta de Poetas Folhas \& Ervas; Sindicato de Artesãos Autônomos de Belém; e Centro de Cultura Libertária (CHAVES..., 1995). Segundo matéria publicada n'O Liberal (FESTA..., 1992), o grupo Ponto de Fuga surgiu no dia 29 de junho de 1991, e sua gibiteca foi criada em agosto do mesmo ano, sendo transferida para a Na Morada da Arte em março de 1992. Funcionava durante as manhãs, de segunda a sexta, e seu acervo era disponibilizado para empréstimos, mediante o pagamento de uma taxa mensal por parte dos interessados.

O Governo Estadual, responsável por ceder o espaço às associações, posteriormente fechou a Na Morada da Arte (VHQ, 2015).

De acordo com Elton Galdino de Lima (2016, p.34), a Biblioteca Pública Arthur 
Vianna, no "Centur", já abrigava um acervo de quadrinhos no ano de 1991, quando as revistas se encontravam acumuladas em um espaço que carecia de condições adequadas de conservação e catalogação. Tal quadro começou a mudar a partir da atuação dos integrantes do Ponto de Fuga, e, em especial, do papel desempenhado por Gian Danton, que foi o autor do projeto de implantação da gibiteca.

Foi apenas em maio de 1993 que a gibiteca da Biblioteca Arthur Vianna ganhou seu espaço particular, sob a coordenação de Gian Danton. A ocasião contou até mesmo com o lançamento de um fanzine da gibiteca, além de um mês de programações, traduzidas em bate papos sobre quadrinhos, oficinas de fanzine e painel sobre as adaptações de cinema e televisão para os quadrinhos (BIBLIOTECA..., 1993). De fato, além das contínuas necessidades de organização/catalogação e renovação do acervo da gibiteca, o espaço também passou a promover atividades de incentivo à leitura e à produção de quadrinhos. Chegou até mesmo a desenvolver atividades experimentais de utilização de quadrinhos em sala de aula, com alunos da $4^{a}$ série da Escola Estadual de Ensino Fundamental Stélio Maroja (HQS..., 1998). E, no que concerne ao quesito produção, temos que a gibiteca se tornou local de encontro para autores de fanzines belenenses, onde trocavam tanto seus fanzines produzidos como também suas próprias experiências de criação (O TRAÇO..., 1998, p.9).

Mesmo nos fanzines podemos encontrar vestígios $\mathrm{da}$ importância $\mathrm{da}$ gibiteca para os seus respectivos autores, quando, por exemplo, indicam-na como posto de informaçóes aos interessados em adquirir o material, ou quando apelam para que o leitor faça doação de HQs "em bom estado para leitura":

Por fim, a terceira gibiteca que
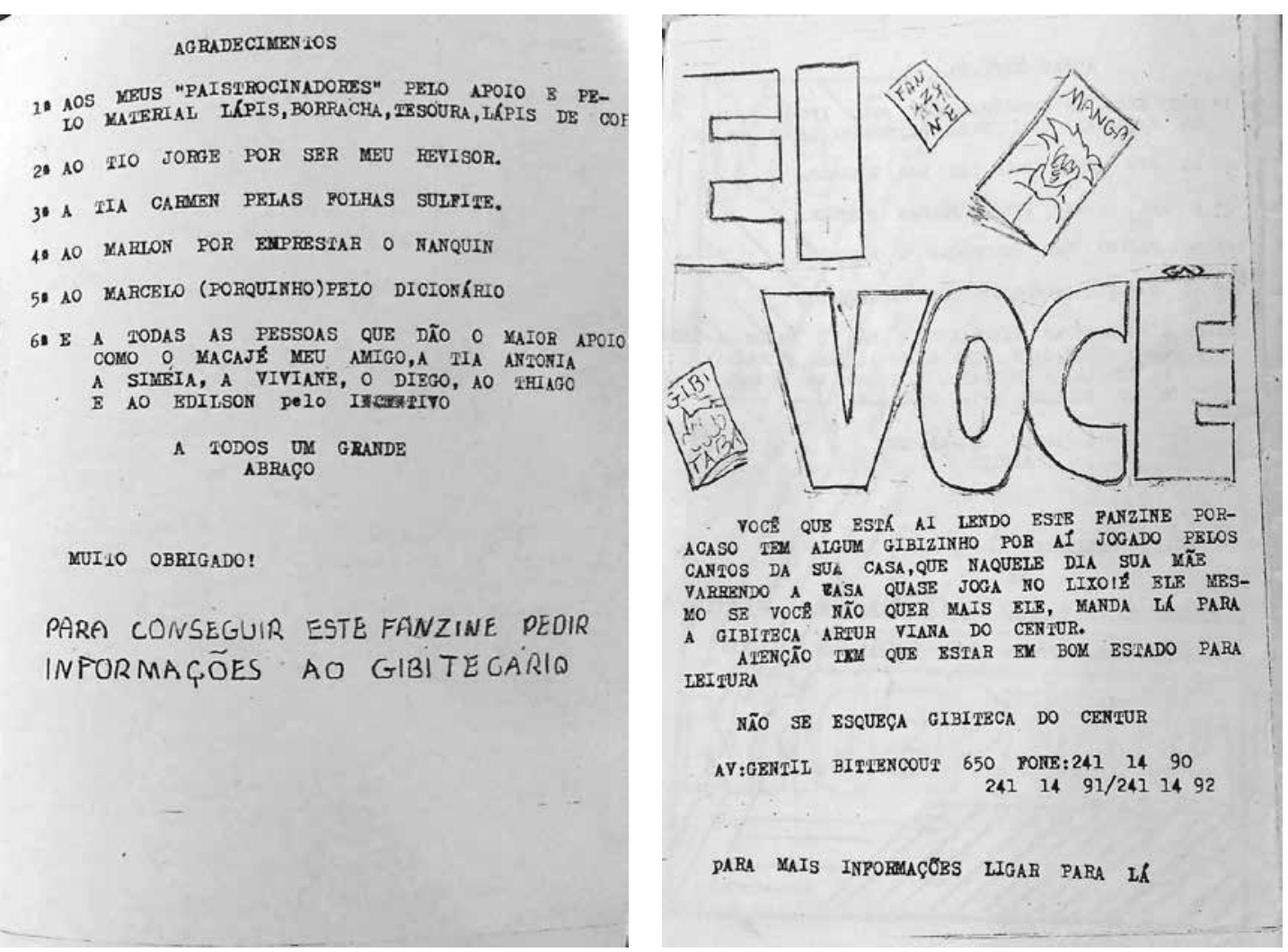

Figuras 2 e 3 - Página final e contracapa do fanzine Barra Pesada, $n^{\circ}$ 2, de Maylson Livio. Fonte: Acervo da autora. 
9. Entrevista concedida a Juliana Angelim, em 29 de junho de 2017.

10. O hoje denominado Núcleo de Oficinas Curro Velho mantém um ciclo de oficinas de iniciação em arte e ofício em diferentes linguagens artes visuais, música, artes cênicas e cursos de capacitação no Núcleo de Práticas de Ofício e Produção -, voltado prioritariamente para um público de estudantes de escola pública, populações de baixa renda e comunidades tradicionais (quilombolas, indígenas e ribeirinhas). Ademais, conta com um calendário de atividades culturais (espetáculos cênicosemusicais, exposições, palestras, rodas de conversa e debates) que tem culminância a cada final de módulo, e, em especial, nos momentos referentes aos ciclos do Carnaval, das Festividades Juninas e do Natal. Localiza-se na Rua Prof. Nelson Ribeiro, no Telégrafo, e abriga a BibliotecaCarmen Sousa, além de salas, teatro, anfiteatro e do acima citado Núcleo de Práticas de Ofício e Produção, para a realização das oficinas, cursos, espetáculos e programações diversas. Disponível em: http://www. fcp.pa.gov.br. Acesso em: 24 jul. 2017. contou com a participação do Ponto de Fuga foi instituída na Casa da Linguagem e teria sido gerenciada por um integrante do grupo, Miguel Imbiriba (também conhecido como Miguel De Lalor). Não obtivemos muitas informações acerca dessa gibiteca, porém, de acordo com Andrei Miralha9 (2017), que também foi membro do Ponto de Fuga, Miguel Imbiriba trabalhava na então Fundação Curro Velho ${ }^{10}$ à época, e lá conseguiu um espaço para as reunióes do grupo. Com efeito, o grupo utilizou os seguintes locais para as suas reuniões: inicialmente, o "Centur" (onde ocorreu a oficina com Bené Nascimento e Gian Danton); em seguida, a Fundação Curro Velho e a Casa da Linguagem (por intermédio de Miguel Imbiriba); até chegarem à sede $\mathrm{da} \mathrm{Na}$ Morada da Arte (NEGRÃO, 2011, p.21).

Das três gibitecas citadas, apenas a instalada na Biblioteca Arthur Vianna permanece ativa nos dias atuais, enquanto que a do Ponto de Fuga foi completamente desfeita e a da Casa da Linguagem se reduziu a uma única estante de revistas em quadrinhos dispostas em caixas-arquivo, localizada junto à Biblioteca Francisco Paulo Mendes. Quanto ao grupo em si, consta que teve diversas formações ao longo de sua trajetória, entremeada por conflitos internos e períodos de não atuação,

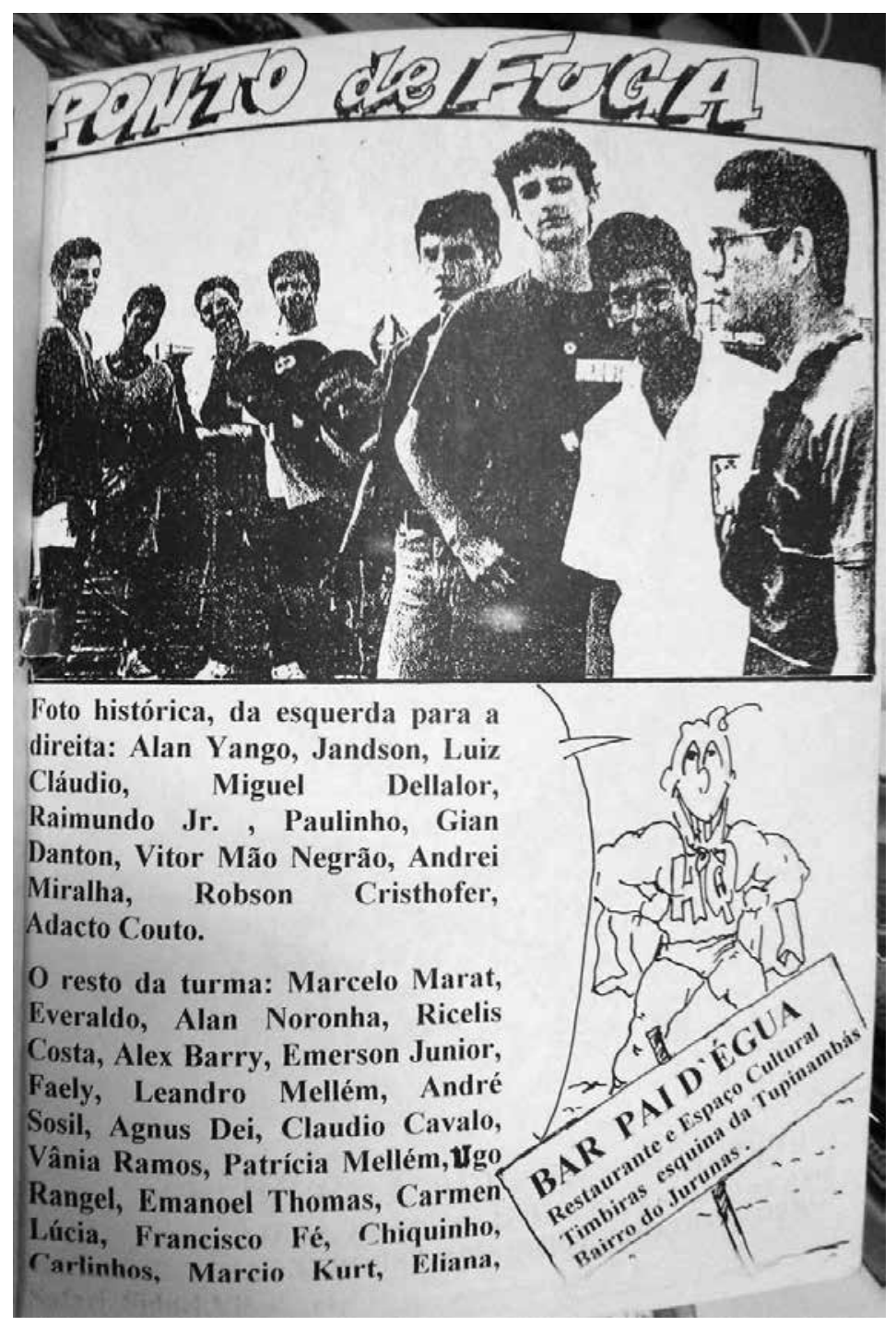

Figura 4 - Página do fanzine Ponto de Fuga n 12, com alguns nomes que integraram o grupo. Fonte: Acervo da autora 
entretanto, mesmo hoje, não houve um término oficial de atividades (NEGRÃO, 2011, p.20). Inclusive, o fanzine lançado em 2011 para comemorar os 20 anos de criação do Ponto de Fuga - este mesmo que estamos usando como fonte para o artigo - é uma das produções mais recentes do grupo, juntamente com a realização de eventos como o Amazônia Comicon, cuja última edição, até o presente momento, ocorreu em 2016.

3 - Os coletivos de quadrinistas e suas publicações

Contemporaneamente ao Ponto de Fuga, surgiu o Boca no Mundo, outro grupo de quadrinistas em Belém. Sua formação também decorreu de uma oficina de quadrinhos, ministrada pelo Lupa abreviação de "Luiz Paulo Jacob", autor do já citado título Vero-Pexe e sua turma (VHQ, 2015): trata-se, especificamente, da I Oficina de Quadrinhos Populares, realizada pela Fundação Curro Velho e a Casa da Linguagem, entre os dias 2 e 20 de dezembro de 1991 (SILVA, 1991). Na ocasião, foi criado o fanzine de estilo underground denominado A Boca no Mundo, que, a partir de 1998, tornou-se La Bouche du Monde, ao passar a ser publicado na França por Eduardo Pinto Barbier, membro original do grupo que se mudou para aquele país e levou consigo o projeto de continuar com o fanzine (VHQ, 2015).

Houve, ainda, a formação de um terceiro grupo, já no ano de 2007. Este, chamado Catarse Quadrinhos, foi encorajado por Miguel Imbiriba, durante a realização de um workshop de quadrinhos no Instituto de Artes do Pará (IAP) ${ }^{11}$. Adnilson Gomes, Adriana Abreu, Cláudio Correia, Eliezer França, Everton Leão, Italo Ferreira, Márcio Silva e Michael Rocha aparecem como a equipe inteira, e, somando aos fanzines produzidos, chegaram a ter uma publicação contemplada pelo Prêmio IAP de Edições Culturais 2008, na categoria de histórias em quadrinhos (LEÃO; PINHEIRO; GOMES, 2008). O grupo possui um blog ${ }^{12}$ na internet, onde, até janeiro de 2012 (data da última atualização), foram postadas histórias em quadrinhos e ilustrações criadas pelos seus membros, além de informações sobre eventos dos quais participaram ou organizaram - dentre eles, a Semana do Quadrinho Nacional de 2012, organizada pelo Catarse com apoio do "Centur".

Embora tenhamos registrado a emergência de apenas três grupos de quadrinistas, cada um deles impulsionado pelo(s) respectivo(s) ministrante(s) de uma oficina ou workshop de quadrinhos, as parcerias entre roteiristas e desenhistas ou entre quadrinistas em geral revela-se uma constante no cenário de quadrinhos da capital paraense, de forma que a maior parte das obras que levantamos trazem em suas capas os nomes de dois ou mais autores. Ainda em matéria de fanzines, temos, por exemplo, o trabalho conjunto de Marcelo Marat (como roteirista) e de Emmanuel Thomaz (como desenhista) na interpretação de letras de bandas paraenses para os quadrinhos (VHQ, 2015), bem como no álbum $O$ Inquilino ${ }^{13}$, lançado em 2009, pela editora Marca de Fantasia.

Destacamos, também, os fanzines resultantes de oficinas de histórias em quadrinhos da Fundação Curro Velho, promovidas, periodicamente, desde o início da Fundação até os dias atuais. E, de fato, ao longo do tempo, permanece significativo o papel da Fundação Cultural do Pará dentro do cenário belenense de histórias em quadrinhos, seja por meio das oficinas ministradas no "Centur", na Casa da Linguagem e no Curro Velho; pelas bolsas do antigo Instituto de Artes do Pará $^{14}$ (que aparecerão novamente logo a seguir); pelas gibitecas implantadas; ou pelos eventos articulados - dentre estes, a já citada Semana do Quadrinho Nacional, sempre no final de janeiro e/ou início de fevereiro, que vem se consolidando como
11. Com endereço na Rua Arcebispo D. Alberto Gaudêncio Ramos, ao lado do Santuário Basílica de Nazaré, o Instituto de Artes do Pará (hoje, Casa das Artes) sedia cursos, oficinas, mostras e espetáculos, dispondo da Biblioteca Vicente Salles e de instalações como auditório/cinema, galeria, sala dedança, entre outros. Retirado de: http://www. fcp.pa.gov.br/. Acesso em:24 jul. 2017.

12 Catarse Quadrinhos - Coletivo de autores de Histórias em Quadrinhos. http://catarsehqs.blogspot.com.br/. Acesso em: 24jul.2017.

13. Apesar de o álbum ser de autoria de Marcelo Marat e de Emmanue Thomaz, as histórias nele contidas apareceram originalmente em alguma das 12 edições do fanzine $\mathrm{O}$ inquilino, criado por Marat com o objetivo de se aperfeiçoar no ofício de roteirista e onde ele experimentou a criação de histórias de diversos gêneros como ficção científica, terror e erótico. ApesardeEmmanuelThomaztambém ter participado como desenhista no fanzine "original", dividiu essa função comvários outros desenhistas, inclusive provenientes de outros estados, ao longo das edições (MARAT,200-?, p.2-8).

14. Por tratar-se de uma instituição do Governo do Estado, não devemos ignorar a possibilidade de os incentivos conferidos à produção artística - à produção "quadrinística" neste caso - estarem vinculados a determinada política cultural estatal vigente em um período específico. Compreendemos, por exemplo, a partir de Fernando Gomes e Edilson Silva, que os projetos políticos e culturais defendidos e praticados em prol do resgate e valorização de uma identidade paraense e/ou amazônica nas administrações dos governadores Almir Gabriel (entre 1995 e 2002) e Simão Jatene (de 2003 a 2006) ambos provenientes do Partido da Social Democracia Brasileira (PSDB) -, configuraram-se, de modo geral, como instrumentos de dominação e legitimação social e política; de modo que, amparados pelo prestígio dos artistas patrocinados, esses governantes buscaram construir um discurso hegemônico de caráter regionalista estrategicamente pensado para fortalecer suas respectivas posições políticas (GOMES, SILVA, 2013, p.167193)

A título de reflexão, data de 2002 o lançamento da primeira edição do Concurso de Bolsas de Criação, Experimentação, Pesquisa eDivulgação Artística do antigo Instituto de Artes do Pará (portanto, dentro do mandato de 
Almir Gabriel), que concede incentivo para artistas e produtores locais, objetivando "aprimorar e fortalecer a produção artística do Estado". Disponível em: http://www.fcp.pa.gov. br/noticias/382-casa-das-artes-orientapara-inscricoes-no-edital-de-bolsas. Acesso em: 5 ago. 2017.

15. De acordo com Andrei Miralha, funcionário da Fundação Cultural do Pará e organizador/curador de várias edições da Semana do Quadrinho Nacional, em entrevista concedida a Juliana Angelim, em 29 de junho de 2017, inicialmente, o evento ocorria apenas no dia do quadrinho nacional (30 dejaneiro),atéquesuaprogramação começou a englobar mais dias. Além disso, desde a sua primeira edição (em 1992, com o Ponto de Fuga) até o ano corrente, não foi realizado em todos os anos e em um local fixo; de forma que, enquanto não houve registro de sua ocorrência em alguns anos, em outros, a ocasião do dia do quadrinho nacional teria sido comemorada duas vezes em Belém, em diferentes lugares. Um exemplo deste último caso teria ocorrido em 2012, visto que Miralha conta ter organizado as Semanas dos anos de 2012, 2013 e 2014 na Casa da Linguagem, ao passo que, como vimos anteriormente, o grupo Catarse também realizou o evento no "Centur" naquele ano. A partir de 2015, com a reunião dos espaços culturais sob o nome da Fundação Cultural do Pará, o evento vem ocorrendo regularmente no"Centur". realização regular da Biblioteca Arthur Vianna, no "Centur", desde o ano de $2015^{15}$. Aliás, como parte da programação referente às semanas do quadrinho nacional de 2016 e 2017, houve o lançamento de concursos de quadrinhos, de onde decorreram a publicação de duas coletâneas de HQs (cada uma com 5 histórias), além de prêmios para os participantes contemplados.

A partir dos anos 2000, a produção
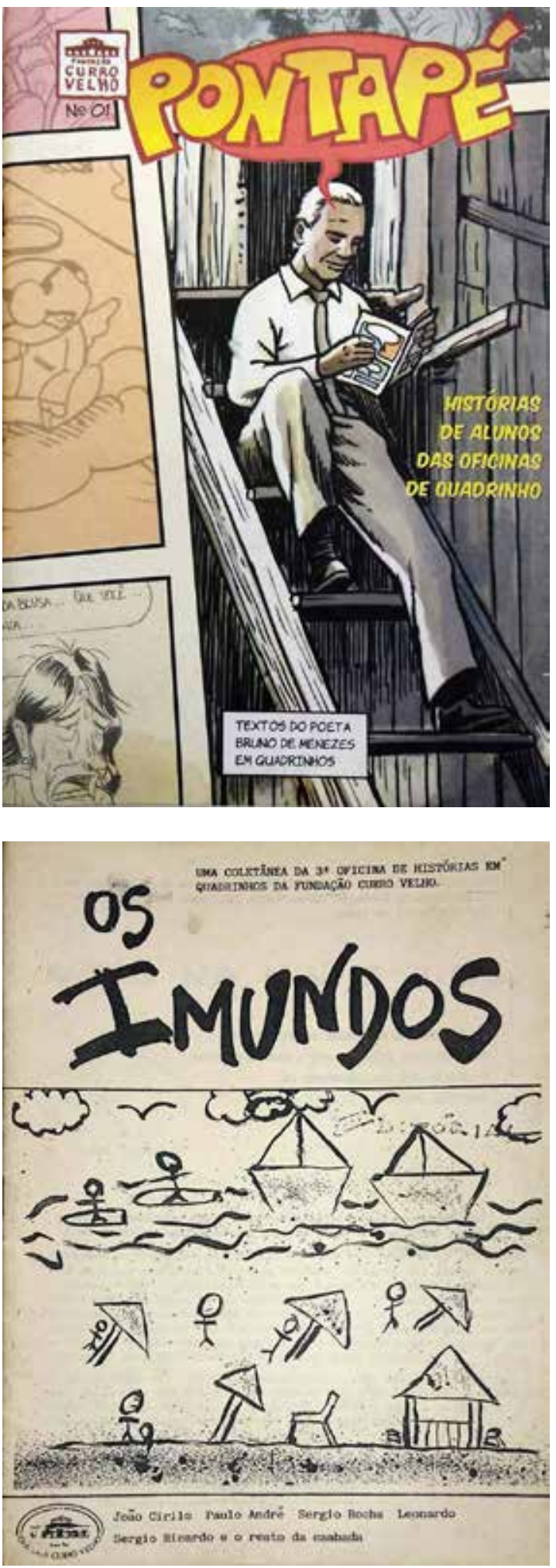

Figuras 5 e 6 - Publicações derivadas de oficinas da Fundação Curro Velho. Fonte: Acervo da autora. 
de fanzines passou a dividir espaço com publicações de melhor acabamento gráfico; lançadas, especialmente, através de iniciativas pessoais dos quadrinistas, de patrocínio governamental (que foi o caso do Catarse Quadrinhos) e, nos últimos anos, de campanhas de financiamento coletivo.

No âmbito das iniciativas pessoais, destaca-se Alan Yango, com o quadrinho independente $O$ Poderoso Maximus. $\mathrm{O}$ personagem que dá nome à $\mathrm{HQ}$ foi apresentado ao público pela primeira vez em 2006, por meio de um blog ${ }^{16}$, e, em 2011, ganhou sua revista física, financiada pelo próprio autor (FERNANDES, 2011). De lá para cá, foram publicadas cinco edições d'O Poderoso Maximus, sem periodicidade definida e algumas delas contando com patrocínios privados, sendo a mais recente datada de abril de 2016. Vale destacar, ainda, que temos aqui outro exemplo de parceria entre quadrinistas, uma vez que Alan Yango cria os roteiros das histórias e convida amigos desenhistas - Bené Nascimento é um deles - para produzirem as ilustrações ${ }^{17}$. A atuação de Yango para manter a publicação contínua de um título de revista em quadrinhos belenense parece ser a mais bem sucedida até agora; contudo, não foi isolada nem pioneira: já em 2007, Diogo Tavares Costa lançou a primeira edição de Ecos Sombrios, chegando, até onde tomamos conhecimento, ao número 3 da revista, além de ter apresentado o personagem Guardião em uma revista intitulada Universo D.T.C. Podemos citar, também, a tentativa encabeçada por Tonico Silva e Álvaro Andrade (2008) de publicar bimestralmente uma coletânea de quadrinhos denominada Quadrinorte, mas chegando a lançar apenas a edição de número 1.

Se, por um lado, a produção de revistas em quadrinhos periódicas em
Belém tem carecido de circunstâncias favoráveis à manutenção destas, por outro, surgem alternativas que beneficiam as publicações em edição única. E é nessa conjuntura que emerge mais um grupo de quadrinistas na cidade, formalmente conhecido como Estúdio Casa Velha. Nas palavras de um dos seus integrantes, Volney Nazareno,

O grupo Casa Velha antes era uma logo apenas, era "Old house", a criação do Carlos [Paul] e do Fernando [Augusto], e eu perguntei a eles se eles poderiam ceder isso pra gente. Por que? Porque élegal tu colocar um nome, fantasia, algo ali, e "Casa Velha" é algo que soa legal. $\mathrm{O}$ que era o Casa Velha? Era um barraquinho lá na casa do Carlos onde a gente se encontrava. ${ }^{18}$

Desses encontros, sucederam duas novelas gráficas cujos nomes são facilmente lembrados ao se falar em quadrinhos belenenses, dado o reconhecimento que obtiveram inclusive em escala nacional. São elas: Belém Imaginária e Encantarias - a lenda da noite. De autoria de Volney Nazareno, Carlos Paul, Fernando Augusto e Otoniel Oliveira, Belém Imaginária foi lançada em 2004, como resultado da Bolsa de Pesquisa, Criação e Experimentação Artística do Instituto de Artes do Pará referente àquele ano (NAZARENO et al, 2004). Segundo Volney ${ }^{19}$, a empolgação por fazer a primeira história em quadrinhos foi tão grande que o grupo de quatro rapazes resolveu buscar patrocínio junto ao Banco da Amazônia para produzir uma segunda, e, em face da resposta positiva, no ano seguinte, publicaram a novela gráfica Encantarias.

Posteriormente, em 2008, a Bolsa de Pesquisa, Criação e Experimentação
16. QG do Maximus. http:// maximuscomix.zip.net/. Acesso em: 5 ago. 2017.

17. Entrevista concedida a Juliana Angelim, em 3 de maio de 2017.

18. Entrevista concedida a Juliana Angelim, em 25 de junho de 2017.

19. Entrevista concedida a Juliana Angelim, em 25 de junho de 2017. 

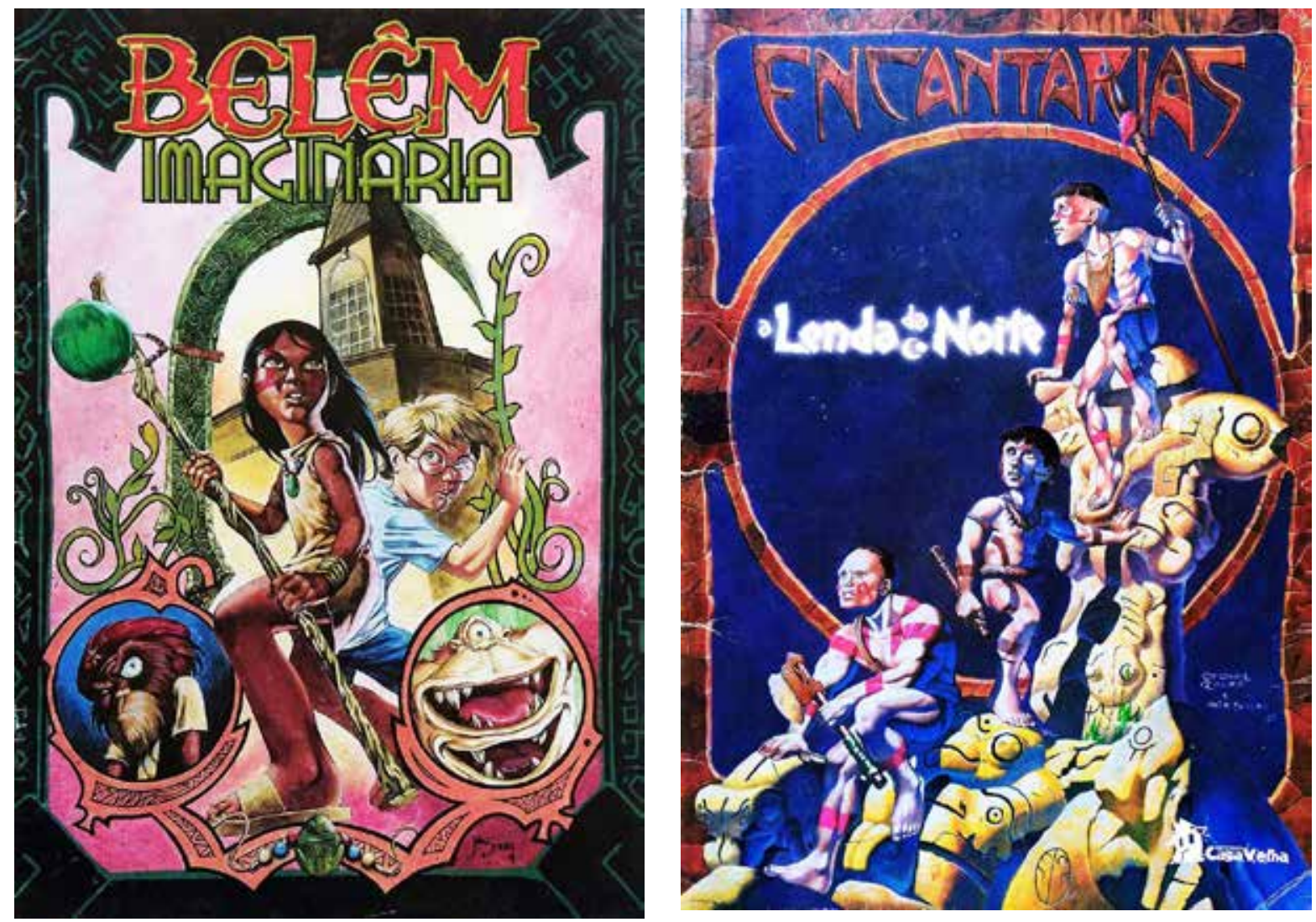

Figuras 7 e 8 - Capas das duas novelas gráficas produzidas pelo Estúdio Casa Velha. Fonte: Acervo de Juliana Angelim.

20. Disponível em: https://www. facebook.com/aturmadoacai/. Acesso em:5 ago. 2017.

21. Disponível em: https://twitter.com/ ATURMADOACAl. Acesso em: 5 ago. 2017.

22. Disponível em: https:// aturmadoacai.tumblr.com/. Acesso em:5 ago. 2017.

23.Disponívelem:http://aturmadoacai. blogspot.com.br/. Acesso em: 5 ago. 2017.

24. Disponível em: https:// www.youtube.com/channel/ UCtFhbKycG1ghoXCMo7_Ex2w. Acesso em: 7 ago. 2017.
Artística do Instituto de Artes do Pará que, a essa época, já proibia a impressão de livros em geral por parte dos contemplados - possibilitou a Otoniel Oliveira produzir a exposição de quadrinhos em forma de painéis intitulada Pretérito mais-queperfeito: imagens do passado de Belém (OLIVEIRA, 2015, p.68). Anos depois, em 2014, o quadrinista iniciou uma campanha de financiamento coletivo no site Catarse, objetivando reunir as HQs da exposição em uma versão impressa. Com o êxito do projeto, em 2015, houve o lançamento de Pretérito mais que perfeito, mais um título belenense cuja repercussão ultrapassou as fronteiras do nosso estado. E, recentemente, só no ano de 2016, outros dois projetos de quadrinhos locais tiveram campanhas bem-sucedidas no Catarse: trata-se de Castanha do Pará, de Gidalti Moura Júnior, e de Esquadrão Amazônia, de Alan Yango e Bené Nascimento.

Já fora do quadro de histórias em quadrinhos impressas, porém dentro do conjunto de publicações que despontaram junto ao século XXI, cabe mencionarmos a produção de artistas de quadrinhos belenenses no meio digital, comumente disponibilizada ao público por meio de blogs e redes sociais. É o caso de Rosinaldo Pinheiro, autor das tiras d'A Turma do Açaí no Facebook ${ }^{20}$, Twitter ${ }^{21}$, Tumblr ${ }^{22} \mathrm{e}$ em um blog ${ }^{23}$, chegando até a lançar curtas de animação com seus personagens, os quais podem ser acessados por um canal no Youtube ${ }^{24}$.

\section{Conclusão}

Considerando, com Waldomiro Vergueiro (2011, p.36), que, indo além do material publicado pelas editoras comerciais, o panorama dos quadrinhos no Brasil abrange um mercado composto de "uma ampla e pujante rede de fanzines e revistas alternativas, publicadas de forma artesanal ou com suporte de recursos 
eletrônicos, principalmente a internet", atestamos o desenvolvimento de um significativo mercado de quadrinhos na capital paraense, que abraça títulos distribuídos em bancas de revistas e livrarias; disponibilizados via correios e em espaços específicos (a exemplo de gibitecas e de eventos de quadrinhos na cidade); bem como publicados em blogs e redes sociais de seus autores. Decerto, do início da década de 70 até o presente momento, os quadrinistas belenenses - seja individualmente ou reunidos em grupos ou parcerias - têm produzido e publicado diversas tiras, fanzines e revistas autorais, contando ou não com financiamento/ patrocínio governamental, privado ou coletivo, e obtendo uma visibilidade estritamente local ou reconhecidamente nacional. Permaneçamos atentos, pois, à nona arte em Belém e na Amazônia.

\section{Referências}

ANDRAUS, Gazy. A situação histórico-social dos fanzines no Brasil. In: VERGUEIRO, Waldomiro; SANTOS, Roberto Elísio dos (Org.). A bistória em quadrinhos no Brasil: análise, evolução e mercado. São Paulo: Laços, 2011. p. 179-199.

BELÉM faz quadrinhos. Diário Informática, Belém, 20 out. 1991. Caderno 5, p.... BIBLIOTECA lança seu $1^{\circ}$ fanzine na Gibiteca. O Liberal, Belém, 2 jun. 1993.

CHAVES versus artistas: o $1^{\circ}$ embate. $O$ Liberal, Belém, 1995.

CUNHA, Vladimir. O mundo é dos nerds. O Liberal, Belém, 15. mar. 1993. Suplemento Troppo, v.2, n.71, p. ....

FANZINE paraense em exposição. $O$ Liberal, Belém, 26 Mar. 1992.

FERNANDES, Leonardo. Sim, nós temos um Superman. Diário do Pará, Belém, 7 mar. 2011. FESTA de balóes, trações e ideias para o Ponto de Fuga. O Liberal, Belém, 29 jun.1992. Cartaz 2.

GOMES, Fernando Henrique da Silva; SILVA, Edilson Mateus Costa da. "O Canto das Águas": Fafá de Belém e a política cultural da SECULT/PA. Revista
Estudos Amazônicos, Manaus, Programa de Pós-Graduação em História Social da Amazônia, v. IX, n.2, 2013.

HQS vão às salas de aula. A Provincia do Pará, Belém, 23 jun.1998.

LEÃO, Everton; PINHEIRO, Alex; GOMES, Adnilson. Catarse Quadrinhos. Belém: IAP, 2008.

LIMA, Elton Galdino de. Grupo Ponto de Fuga: o quadrinho em Belém entre os anos de 1991 e 1996. 2016. (Trabalho de Conclusão de Curso - Licenciatura/Bacharelado em Artes Visuais) Universidade Federal do Pará, 2016.

LOUREIRO, João de Jesus Paes. Está lançado o quadrinho. Folha do Norte, Belém, 4 fev. 1972. Caderno 2, p. 2.

MARAT, Marcelo. O Inquilino, Belém, n. 12, 200-?.

NAZARENO, Volney et al. Belém Imaginária. Belém: IAP, 2004.

NEGRÃO, Luiz Cláudio Martins (ed.). Ponto de Fuga 20 anos. Belém: out. 2011.

O TRAÇO nosso de todo dia. Os verdadeiros "fanáticos" por fanzines. Mão Livre, Belém, n. 9, out.1998.

OLIVEIRA, Otoniel. Pretérito mais que perfeito. Belém: Ed. do Autor, 2015.

SAKS, Daniel (ed). Calafrio: H.Q. de terror em nova dimensão! Curitiba, n.56, nov. 2016.

SILVA, Lucia. et al. A Boca no Mundo, Belém, n. 1, dez. 1991.

SILVA, Tonico; ANDRADE, Álvaro (Coord.). Quadrinorte: quadrinhos do Pará, Belém, Set. 2008.

VERGUEIRO, Waldomiro. Desenvolvimento e tendências do mercado de quadrinhos no Brasil. In: VERGUEIRO, Waldomiro; SANTOS, Roberto Elísio dos (org.). A bistória em quadrinhos no Brasil: análise, evolução e mercado. São Paulo: Laços, 2011.p. 13-56.

VHQ: uma breve bistória dos quadrinhos paraenses. Direção e roteiro: Vince Souza. Produção: Bianca D'Aquino, Leriton Brito, Thamires Rafael e Vince Souza. Belém: Café, Cinema e Quadrinhos, 2015. Documentário, 51'13". 